\title{
Biochemical and cell wall ultrastructural changes in crown tissue of banana (Musa AAA 'Berangan') fruit as mediated by UVC irradiation against crown rot fungal infection
}

\begin{abstract}
The reduction of crown rot disease observed in UVC-irradiated banana fruit, 'Berangan' was associated with activation of the defense response mechanisms, increased peroxidase and polyphenol oxidase activities as well as accumulation of lignin and phenolic compounds in its crown tissue, but not phenylalanine ammonia-lyase activity. Transmission electron microscope micrographs revealed that $0.01 \mathrm{~kJ} \mathrm{~m}^{-2}$ UVC retarded the losses of cell compartments and disintegrations of fibril fraction in cell wall structure of the crown tissue. UVC treatment $24 \mathrm{~h}$ after fungal inoculation induced the accumulation of phenol-storing cells that could create an antimicrobial environment in the host tissue for combating the fungal colonization. Moreover, formation of cell wall lignification and heterogenous matrix of cell wall appositions at site of fungal penetration was clearly observed in UVC-irradiated crown tissue, which otherwise absent in the control crowns. These structures might be important physical barriers that were induced by the irradiation to prevent diffusions of toxin and enzyme from the crown rot-infecting fungi.
\end{abstract}

Keyword: UVC; Peroxidase; Polyphenol oxidase; Phenylalanine ammonia-lyase; Cell wall lignification; Cell wall apposition 